\title{
Mining
}

\section{Minimum/Maximum Autocorrelation Factors Applied to Grade Estimation}

\section{Fatores de mínimas/máximas autocorrelações aplicada à estimativa de teores}

\begin{abstract}
Camilla Zacché da Silva
Physicist, PhD candidate, Mining Engineering Department, Federal University of Rio Grande do Sul - Departamento de Engenharia de Minas camilla.zacche@gmail.com
\end{abstract}

João Felipe Coimbra Leite Costa Associate Professor

Mining Engineering Department, Federal

University of Rio Grande do Sul

jfelipe@ufrgs.br

\begin{abstract}
It is frequent to face estimation problems when dealing with mineral deposits involving multiple correlated variables. The resulting model is expected to reproduce data correlation. However, is not guaranteed that the correlation observed among data will be reproduced by the model, if the variables are estimated independently, and this correlation is not explicitly taken into account. The adequate geostatistical approach to address this estimation problem is co-kriging which requires cross and direct covariance modeling of all variables, satisfying the LMC. An alternative is to decorrelate the variables and estimate each independently, using for instance, the minimum/maximum autocorrelation factors (MAF) approach, which uses a linear transformation on the correlated variables, transforming them to a new uncorrelated set. The transformed data can be estimated through kriging. Afterwards, the estimates are back-transformed to the original data space. The methodology is illustrated in a case study where three correlated variables are estimated using the MAF method combined with kriging and through co-kriging, used as a benchmark. The results show less than a $2 \%$ deviation between both methodologies.
\end{abstract}

Keywords: minimum/maximum autocorrelations factors; geostatistics; kriging.

\section{Resumo}

$\mathrm{Na}$ indústria mineira, a estimativa de múltiplas variáveis correlacionadas é comum, na qual os modelos devem reproduzir a correlação exibida pelos dados. Porém, se as variáveis forem estimadas individualmente por krigagem e a informação da correlação não for incorporada explicitamente, não há garantia de que a correlação observada nos dados será reproduzida. A abordagem clássica para estimativa de múltiplas variáveis correlacionadas, cokrigagem, exige um modelo que satisfaça as condições de positividade impostas pelo modelo linear de corregionalização, condição que torna essa metodologia extremamente laboriosa, quando há mais de duas variáveis. Uma alternativa à cokrigagem é descorrelacionar as variáveis e as estimar de forma independente. Para isso, pode-se utilizar de fatores de mínimas/máximas autocorrelações (MAF), aplicando-se uma transformação linear nos dados, transformando-os em outro conjunto descorrelacionado. Os novos fatores calculados, a partir dos dados, podem ser estimados através de krigagem individualizada. Essa metodologia é ilustrada por meio de um estudo de caso, no qual três variáveis correlacionadas são estimadas, aplicando krigagem aos MAF, denominados de KMAF. A cokrigagem é utilizada, aqui, como referência. Os resultados apresentam menos de $1 \%$ de desvio relativo.

Palavras chave: Fatores de mínimas Imáximas autocorrelaçoes, geoestatística, krigagem. 


\section{Introduction}

Geostatistical applications dealing with multiple, possibly-correlated variables are becoming more frequent in mineral resources estimation. If there is a spatial correlation between two or more variables and one variable is more sampled than the others (i.e., a heterotopic situation), then the densely sampled variable can be used in combination to estimate the other, under-sampled variables. The classic approach to multivariate problems in grade estimation is co-kriging (MARECHAL, 1970), which considers not only direct covariances, as in ordinary and simple kriging (MATHERON, 1963), but also the cross-covariances between every variable in the data set. Consequently this approach capitalizes on the existing correlation between all variables and

\section{Methodology}

\section{Theoretical Foundations}

The Minimum/Maximum Autocorrelation Factors was first used to sepa-

where $\mathbf{a}_{\mathrm{i}}^{\mathrm{t}}$ is the transpose eigenvector of the transformation matrix $\mathrm{A}$, such that the MAF factors $M_{i}(u)$ show increasing autocorrelation with increscent $i$; in other words, the factor shows higher spatial provides a more accurate estimate. Nevertheless, one of the great drawbacks in the use of co-kriging is the need to satisfy the linear model of co-regionalization (LMC), which requires the direct and cross variograms to be a linear combination of basic structures. This assumption guarantees that the linear combination variance is always positive (GOOVAERTS, 1997). To build a valid LMC is not trivial, and in fact it is difficult when dealing with more than two correlated variables. Consequently, there is a need for simpler yet accurate and precise alternatives to handle multivariate estimation problems. One such approach is principal component analysis (PCA) (PEARSON, 1901), where an observation vector, $\phi(u)=\left[U_{1}(u), U_{2}, \ldots U_{N}(u)\right]$, is rotated in space through a linear transformation

rate noise and signal components from multispectral images obtained by remote sensors (SWITZER and GREEN, 1984). According to Switzer and Green (1984),

$$
M_{i}(u)=\mathbf{a}_{i}^{t} \phi(u)
$$

autocorrelation than the factor $M_{2}(u)$ (SWITZER and GREEN, 1984).

The MAF factors are obtained through a spectral decomposition of the matrix , where is the covariance matrix that takes the $N$ variables in the data set to a new space where they are no longer correlated. As a consequence, each factor can be treated independently, avoiding the need to satisfy the LMC, and reducing the problem to one of ordinary kriging. PCA, however, has a limitation: decorrelation is not guaranteed for a non-zero separation vector, $h$, unless there is an intrinsic correlation between the data (BANDARIAN ET AL., 2008). An alternative to PCA is the minimum/maximum autocorrelation factors (MAF) approach (SWITZER and GREEN, 1984), which, like PCA, applies a linear transformation to the data set taking it to a new space where no correlation is present. In this new space, decorrelation is guaranteed for all data separated by a non-zero vector, $h$.

MAF consists in transforming a multivariate random vector $\phi(u)=\left[U_{1}(u), U_{2}, \ldots U_{N}(u)\right]$ into a set of linear combinations that are independent from each other,

$\operatorname{Cov}_{\phi \delta} \operatorname{Cov}_{\phi}^{1}$, where $\operatorname{Cov}_{\phi}$ is the covariance matrix for $\phi(u)$ for $b=0$ and $\operatorname{Cov}_{\phi}^{-1}$ is its inverse. $\operatorname{Cov}_{\phi \delta}$ is the covariance matrix for differences of vectors separated by $b=\delta$; in other words,

$$
\operatorname{Cov}_{\phi}=\operatorname{Cov}[\phi(u), \phi(u)]
$$

$$
\text { and } \operatorname{Cov}_{\phi \delta}=\operatorname{Cov}[(\phi(u)-\phi(u+\delta)),(\phi(u)-\phi(u+\delta))]=2 \Gamma_{\phi}(\delta)
$$

where $\Gamma_{\phi}(\delta)$ is the variogram matrix for $h=\delta$.

Being the random vector $\phi(u)=\left[U_{1}(u), \ldots, U_{N}(u)\right]^{T}$ stationary and

being, $\operatorname{Cov}_{0}, \operatorname{Cov}_{1}$ and $\operatorname{Cov}_{\phi}$ the variance-covariance matrices for $b=0$ If composed of two components, for example, signal $\mathbf{S}(u)$ and noise $\mathbf{N}(u)$ such that

$\left\{\begin{array}{c}\operatorname{Cov}[\mathbf{N}(u), \mathbf{N}(u)]=\operatorname{Cov}_{\mathrm{N}}(0)=\operatorname{Cov}_{0} \\ \operatorname{Cov}[\mathbf{S}(u), \mathbf{S}(u)]=\operatorname{Cov}_{\mathrm{S}}(0)=\operatorname{Cov}_{1} \\ \operatorname{Cov}[\phi(u), \phi(u)]=\operatorname{Cov}_{0}+\operatorname{Cov}_{1}=\operatorname{Cov}_{\phi}\end{array}\right.$

$\phi(u)=\mathbf{S}(u)+\mathbf{N}(u)$ can be represented by a two structure linear model of co-region-
$\phi(u)=\mathbf{S}(u)+\mathbf{N}(u)$, the variance-covariance matrices are given by:

$$
\left\{\begin{array}{c}
\operatorname{Cov}[\mathbf{N}(u), \mathbf{N}(u+b)]=\operatorname{Cov}_{\mathrm{N}}(b)=\rho_{0}(b) \operatorname{Cov}_{0} \\
\operatorname{Cov}[\mathbf{S}(u), \mathbf{S}(u+b)]=\operatorname{Cov}_{\mathrm{S}}(b)=\rho_{1}(b) \operatorname{Cov}_{1} \\
\operatorname{Cov}[\phi(u), \phi(u+b)]=\operatorname{Cov}_{\phi}(b)=\rho_{0}(b) \operatorname{Cov}_{0}+\rho_{1}(b) \operatorname{Cov}_{1}
\end{array}\right.
$$

alization, the spatial covariance matrices, for a separation vector $h$, are given by:

where $\rho_{0}(b)$ and $\rho_{1}(b)$ and are spatial correlation functions such that $\rho_{1}>$ $\rho_{0}$ for all $h$. Being $\operatorname{Cov}_{\mathrm{N}}(h)$ is the noise component covariance, $\operatorname{Cov}_{S}(b)$ the signal component covariance and $\operatorname{Cov}_{\phi}$ (b) the vector composed by the sum of the noise and signal components covariance. $\operatorname{Cov}_{0}$ and $\operatorname{Cov}_{1}$ are the two covari- ance structures of the co-regionalization model. For $h=\delta$, this results in: 


$$
\operatorname{Cov}[\phi(u)-\phi(u+\delta)],(\phi(u), \phi(u+\delta))]=2 \operatorname{Cov}_{\phi}\left(1-\rho_{1}(\delta)\right)+2 \operatorname{Cov}_{0}\left(\rho_{1}(\delta)-\rho_{0}(\delta)\right)=2 \Gamma_{\phi}(\delta)
$$

where $\Gamma_{\phi}(\delta)$ is the variogram matrix for $b=\delta$.

Switzer and Green (1984) show that the $2 \Gamma_{\phi}(\delta) \operatorname{Cov}^{-1}$ eigenvectors are the same as the $\operatorname{Cov}_{0} \operatorname{Cov}_{\phi}^{1}$ eigenvectors,

i. Calculate the variance-covariance matrix of the random vector $\phi(u)=\left[U_{\mathrm{i}}(u)\right]$ for $h=0, \operatorname{Cov}_{\phi}$. Perform a spectral decomposition on Cov $_{\phi}$ into its matrices of eigenvectors, $\mathrm{H}$ and eigenvalues, D such $\operatorname{Cov}_{\phi}=\mathrm{HDH}^{\mathrm{T}}$ that ;

ii. Calculate the principal compo-

Once the data transformation is applied and the MAF factors obtained, kriging can be used individually on each factor. After the kriging of the factors

i. First, the classical approach to multivariate grade estimation, co-kriging is applied to the data set in order to use its results as a benchmark for the case study.

\section{Data set}

The study was performed on the 2-D Jura data set(GOOVAERTS, 1997), which contains 259 samples of seven isotopic variables, Nickel $(\mathrm{Ni})$, Cadmium (Cd), Chromium (Cr), Cobalt $(\mathrm{Co})$, Lead ( $\mathrm{Pb})$, Zinc $(\mathrm{Zn})$, Copper $(\mathrm{Cu})$. The variables of interest in this case study are the concentrations in ppm of however this is not a symmetric matrix (DESBARATS and DIMITRAKOPOULOS, 2000), and its spectral decompo-

nents $\mathbf{V}(\mathbf{u})$ such that $\mathbf{V}(\mathbf{u})=\mathrm{W}^{\mathrm{T}} \phi(u)$, where $\mathrm{W}=\mathrm{HD}^{-1 / 2}$;

iii. Calculate the variogram matrix $\Gamma_{\mathrm{v}}(b)$ for $h \neq 0$ of the $\mathrm{V}(\mathrm{u})$ set of components; iv. Perform a spectral decomposition $\Gamma_{\mathrm{v}}(h)$ in its matrices of eigenvectors $\mathrm{C}$ and eigenvalues $\Lambda$;

$\mathbf{M}(u)$, it is necessary to back-transform the block model to the original data space. This back-transformation is given by $\phi(u)=\left(\mathbf{A}^{\mathrm{T}}\right)^{-1} \mathbf{M}(u)$, where $\left(\mathbf{A}^{\mathrm{T}}\right)^{-1}$ is the

ii. Afterwards, the MAF transformation is applied to the same data set and is used combined with ordinary kriging, herein denoted as KMAF.

\begin{tabular}{c|c|c|c}
\hline & Co & Cr & Ni \\
\hline Mean $(\mathrm{ppm})$ & 9.30 & 35.07 & 19.73 \\
\hline $\begin{array}{c}\text { Declustered } \\
\text { mean }(\mathrm{ppm})\end{array}$ & 9.45 & 35.65 & 20.7 \\
\hline
\end{tabular}

$\mathrm{Ni}$, Co, andCr, which are correlated. These three variables have a correlation coefficient, $\rho_{\mathrm{CoNi}}=0.75$ between Cobalt and Nickel; $\rho_{\mathrm{CoCr}}=0.45$ between Cobalt and Chromium; $\rho_{\mathrm{NiCr}}=0.69$ between Nickel and Chromium. Cokriging is a natural choice to estimate simultaneously correlated variables. The sition is not trivial; the MAFsolution, therefore can be obtained through five steps:

v. Finally, perform the data transformation $\phi(u)=\left[U_{\mathrm{i}}(u)\right]$ into a set of MAF factors, $\mathbf{M}(u)=\left[M_{i}(u)\right]$, through the transformation matrix $\mathrm{A}=\mathrm{WC}$, such that $\mathbf{M}(u)=\mathbf{A}^{\mathrm{T}} \phi(u)$.

transformation matrix inverse.

In the sequence of this study, developed are the following steps:

iii. Finally, the results of (i) and (ii) are validated and compared to verify the applicability of the KMAF approach forgrade estimation of multivariate data. data has an average sampling spacing of $250 \mathrm{~m}$ along $\mathrm{X}$ and $\mathrm{Y}$ directions, presenting clustered samples at some regions. To decluster the data set, the Voronoi Polygon algorithm (DIRICHLET, 1850) was used. The declustered data statistics are shown in Table 1.

Table 1

Statistical summary for the variables Co, $\mathrm{Cr}$ and $\mathrm{Ni}$. Concentrations in ppm.

together; the preferential sampling caused a downward bias on the global means. study variables, the declustered mean is higher than the original clustered mean. Most clusters in the data set were

\section{Co-kriging}

The variables Co (ppm), Cr (ppm) and $\mathrm{Ni}(\mathrm{ppm})$ were co-estimated by co-kriging. The method requires direct semi-variograms for Co (ppm), $\mathrm{Cr}(\mathrm{ppm})$ and $\mathrm{Ni}(\mathrm{ppm})$ as well as the located in low-grade regions for all three variables, since it is an isotopic data set and they all have direct correlation, which means that all variables increase

\begin{tabular}{c|c|c|c|c|c}
\hline Number of lags & Lag size & $\begin{array}{c}\text { Lag } \\
\text { tolerance }\end{array}$ & $\begin{array}{c}\text { Number of } \\
\text { directions }\end{array}$ & $\begin{array}{c}\text { Angular } \\
\text { tolerance }\end{array}$ & Band width \\
\hline 10 & $250 \mathrm{~m}$ & $100 \mathrm{~m}$ & 8 & 22.5 & $100 \mathrm{~m}$ \\
\hline
\end{tabular}

cross-covariogram between Co (ppm) and $\mathrm{Cr}$ (ppm), Co (ppm) and $\mathrm{Ni}$ (ppm), $\mathrm{Cr}(\mathrm{ppm})$ and $\mathrm{Ni}(\mathrm{ppm})$. The experimental semi-variogram for Co (ppm) was modeled first, and this was then used to determine the semi-variograms for $\mathrm{Cr}(\mathrm{ppm})$ and $\mathrm{Ni}(\mathrm{ppm})$ and all crosscovariograms.Table 2 summarizes the parameters used for the experimental semi-variograms. 
The major anisotropy direction is N45 with a $1000 \mathrm{~m}$ range and zero dip, the minor anisotropy direction is $\mathrm{N} 135$

with a $500 \mathrm{~m}$ range and zero dip.The fit-

ted model is:

$$
\gamma=\mathrm{C}_{0}+\mathrm{C}_{1} \mathrm{Sph}\left(\frac{800 \mathrm{~m}}{\mathrm{~N} 45} \frac{400 \mathrm{~m}}{\mathrm{~N} 135}\right)+\mathrm{C}_{2} \mathrm{Sph}\left(\frac{1000 \mathrm{~m}}{\mathrm{~N} 45} \frac{500 \mathrm{~m}}{\mathrm{~N} 135}\right)
$$

being the nugget effect, the sill of the first spherical structure and the sill of the second spherical structure. The co-regionalization matrices are:

$$
C_{0}=\left[\begin{array}{ccc}
0.88 & 1.7 & 2.2 \\
1.7 & 24.02 & 6.24 \\
2.2 & 6.24 & 7.62
\end{array}\right] \quad C_{1}=\left[\begin{array}{ccc}
0.88 & 0.66 & 2.011 \\
0.66 & 18.91 & 0.75 \\
2.011 & 0.75 & 5.12
\end{array}\right] \quad C_{2}=\left[\begin{array}{ccc}
11 & 15.3 & 17.85 \\
15.31 & 77.74 & 55.16 \\
17.85 & 55.16 & 55.04
\end{array}\right]
$$

The co-kriging parameters are presented in Table 3.

Table 3

Co-kriging parameters

\begin{tabular}{c|c|c|c|c}
\hline $\begin{array}{c}\text { Minimum conditional } \\
\text { data }\end{array}$ & $\begin{array}{c}\text { Maximum conditional } \\
\text { data }\end{array}$ & Azimuth & $\begin{array}{c}\text { Ellipsoid } \\
\text { radii }\end{array}$ & $\begin{array}{c}\text { Block } \\
\text { discretization } \\
\text { (X/Y/Z) }\end{array}$ \\
\hline 2 & 8 & $\mathrm{~N} 45$ & $800 \mathrm{~m} / 400 \mathrm{~m}$ & $5 / 5 / 1$ \\
\hline
\end{tabular}

\section{Kriging with MAF Transformation (KMAF)}

The MAF factors were obtained using an algorithm based on the Methodology section above. The value used to calculate the variogram matrix was $500 \mathrm{~m}$, less than the range of the first spherical range of the semi-variogram and twice the average sampling spacing. To validate the spatial decorrelation of the factors, the following procedure was adopted. First, the factors were backtransformed to the original values to check if the algorithm would bring the MAF factors to the original space. Next, the cross-correlograms of the factors
MAF1, MAF2 and MAF3 were plotted in order to check their spatial decorrelation. The next step, once the decorrelation is verified, is to krig each factor independently. The block-kriged MAF factors are finally back-transformed to the original space, where the results can be checked and analyzed.The experimental semi-variograms for each factor were calculated and plotted using the parameters in Table 2.

The spatial continuity directions for all three MAF factors are the same as the original variables: the major an- isotropy direction is N45 with zero dip; the minor anisotropy direction is N135 with zero dip.

The major range for MAF1 is 1800 $\mathrm{m}$ along N45 with zero dip, the minor range is $1000 \mathrm{~m}$ along the N135 with zero dip.The major range for the factor MAF2 is $1600 \mathrm{~m}$ along N45 with null dip, the minor range is $1000 \mathrm{~m}$ along N135 with null dip. For MAF3 factor the major range is $1500 \mathrm{~m}$ along $\mathrm{N} 45$ with null dip, the minor range is $1000 \mathrm{~m}$ along the N135 with null dip. The fitted models are:

$$
\begin{aligned}
& \gamma_{\text {MAF1 }}=0.3+0.25 \mathrm{Sph}\left(\frac{500 \mathrm{~m}}{\mathrm{~N} 45} \frac{500 \mathrm{~m}}{\mathrm{~N} 135}\right)+0.45 \mathrm{Sph}\left(\frac{1800 \mathrm{~m}}{\mathrm{~N} 45} \frac{1000 \mathrm{~m}}{\mathrm{~N} 135}\right) \\
& \gamma_{\mathrm{MAF} 2}=0.4+0.2 \mathrm{Sph}\left(\frac{500 \mathrm{~m}}{\mathrm{~N} 45} \frac{500 \mathrm{~m}}{\mathrm{~N} 135}\right)+0.4 \mathrm{Sph}\left(\frac{1600 \mathrm{~m}}{\mathrm{~N} 45} \frac{1000 \mathrm{~m}}{\mathrm{~N} 135}\right) \\
& \gamma_{\mathrm{MAF3}}=0.2+0.1 \mathrm{Sph}\left(\frac{500 \mathrm{~m}}{\mathrm{~N} 45} \frac{500 \mathrm{~m}}{\mathrm{~N} 135}\right)+0.7 \mathrm{Sph}\left(\frac{1500 \mathrm{~m}}{\mathrm{~N} 45} \frac{1000 \mathrm{~m}}{\mathrm{~N} 135}\right)
\end{aligned}
$$

Using these models, each factor is estimated using ordinary kriging with the parameters shown in Table 3.

\section{Results and discussion}

\section{Global mean reproduction}

The global mean obtained through both methods were compared against the original declustered means of Co (ppm), $\mathrm{Cr}(\mathrm{ppm})$ and $\mathrm{Ni}$ (ppm). The relative deviation, between the estimated means with respect to the declustered data mean was used to check for global bias. The results are shown in Table 5 . 


\begin{tabular}{c|c|c|c|c|c}
\hline & Declustered mean & Co-kriged mean & KMAF mean & (err\%) co-kriging & (err\%) KMAF \\
\hline $\mathrm{Co}(\mathrm{ppm})$ & 9.45 & 9.36 & 9.46 & $-0.95 \%$ & $0.1 \%$ \\
\hline $\mathrm{Cr}(\mathrm{ppm})$ & 35.65 & 36.00 & 35.91 & $1.12 \%$ & $0.72 \%$ \\
\hline $\mathrm{Ni}(\mathrm{ppm})$ & 20.70 & 20.65 & 20.63 & $-0.24 \%$ & $-0.33 \%$ \\
\hline
\end{tabular}

Note in Table 5 that both methods reproduced the data global mean for all variables, with low relative deviation (less than $1 \%$ deviation).The higher relative deviation was obtained through cokriging for $\mathrm{Cr}$ (ppm), which is the least

correlated variable in the co-estimation system. Since the co-kriging model was based on the Co (ppm) variable, and these two variables are poorly correlated; this may be an indication that the LMC model built is not as adequate for
Table 5

Comparison of the block-model global mean against the declustered data mean

the $\mathrm{Cr}$ (ppm) variable as for Co (ppm). Even so, the relative deviation is not significant. Meanwhile, with respect to the co-kriging approach, the KMAF method showed less than $2 \%$ relative difference.

\section{Swath Plots}

Tests to check for local bias were also performed. The local mean behavior was

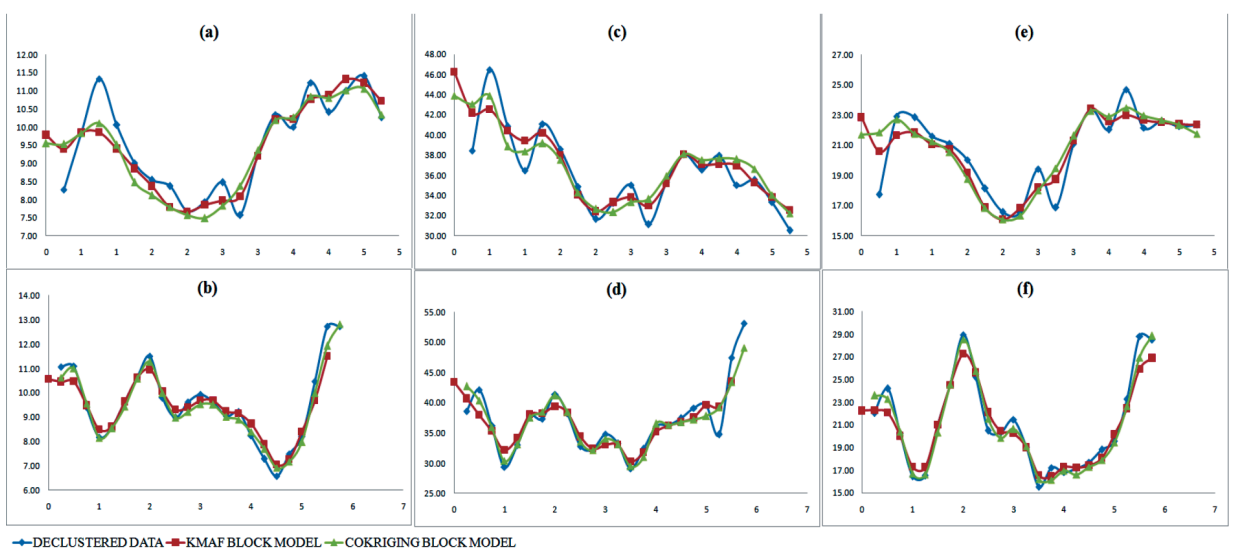

Note in figure 1 that the estimated block models follow the local trend mean, and the smoothing effect is evident in all graphs in figure 1. In figure 1 (a) and (b) for Co (ppm), it is seen that the co-kriged block model underestimates the mean, and is more apparent than the one seen on the KMAF block model, especially examined using swath plots along the $\mathrm{X}$ and $Y$ directions. Figs. 6 and 7 show swath plots for Co (ppm), $\mathrm{Cr}$ (ppm) and $\mathrm{Ni}$ (ppm) along the $\mathrm{X}$ and $\mathrm{Y}$ directions.

Figure 1

Swath plots of the declustered data and estimated block models. (a) Co (ppm) along the $\mathrm{X}$ direction; (b) Co (ppm) along the $Y$ direction; (c) $\mathrm{Cr}$ (ppm) along the $X$ direction; (d) $\mathrm{Cr}$ (ppm) along the $Y$ direction; (e) Ni (ppm) along the $\mathrm{X}$ direction and (f) $\mathrm{Ni}(\mathrm{ppm})$ along the $\mathrm{Y}$ direction. The vertical axis is the variable mean concentration in (ppm) and the horizontal axis is the band width in kilometers.

block model sometimes overestimates the declustered data mean while at other times, underestimates it, presenting very close behavior between the block models. In graphs (e) and (f), evident is the underestimation of the declustered data mean by both estimated block models, having also very close behavior between them.

\section{Correlation of Variables}

The correlation between the variables $\mathrm{Co}(\mathrm{ppm}), \mathrm{Cr}(\mathrm{ppm})$ and $\mathrm{Ni}(\mathrm{ppm})$ was checked in each interpolated block model (Table 6).

\begin{tabular}{c|c|c|c|c|c}
\hline Pair & Original correlation & KMAF & Co-kriging & $\begin{array}{c}\text { Relative deviation } \\
\text { for KMAF }\end{array}$ & $\begin{array}{c}\text { Relative deviation } \\
\text { for co-kriging }\end{array}$ \\
\hline $\mathrm{Co} \times \mathrm{Cr}$ & 0.45 & 0.53 & 0.60 & $17.7 \%$ & $33.3 \%$ \\
\hline $\mathrm{Co} \times \mathrm{Ni}$ & 0.75 & 0.78 & 0.79 & $4 \%$ & $5.3 \%$ \\
\hline $\mathrm{Cr} \times \mathrm{Ni}$ & 0.69 & 0.68 & 0.74 & $1.4 \%$ & $7.2 \%$ \\
\hline
\end{tabular}

Note in Table 6 that the correlation between the variables is better reproduced by the KMAF block model. For the Co (ppm) versus $\mathrm{Cr}$ (ppm) pairs, the original correlation was $\rho=0.45$ which is the lowest correlation coefficient amongst the variables in the data set. For the KMAF approach, the correlation was overestimated by around $17 \%$. The co-kriged block model also
Table 6

Correlation coefficients for $\mathrm{Co}(\mathrm{ppm})$, $\mathrm{Cr}(\mathrm{ppm})$ and $\mathrm{Ni}(\mathrm{ppm})$ block models ( $\mathrm{KMAF}$ and co-kriging), together with the deviation from the original data correlation.

overestimated this pair's correlation, around 33\% higher than the original value. This overestimation is due the fact the block model has way more pairs to plot, which in case of a spurious cor- 
relation, can increase its value. As for the other correlations observed in the

\section{Cross validation}

Cross validation was performed, as part of the result analysis for both block models derived from KMAF and cokriging. Note that for KMAF, the cross validation is performed on the MAF factors block model and afterwards, back-transformed to the original data space. For the co-kriging approach, the cross validation was performed ignoring all variables on one entire sample, so it is as if it was done usingthe kriging approach and no variable generated bias during the estimation verification.

The correlation coefficient be-

\section{Conclusions}

It has been shown that for this case study, the mean global grade is reproduced by KMAF and by co-kriging with less than a $2 \%$ deviation. The KMAF approach obtained a more accurate local grade estimate, being confirmed by the swath plots. The correlation between variables was more accurate using the KMAF estimation. Remember that this approach builds an individual estimation model for each factor; therefore

\section{Acknowledgements}

The authors would like to thank the Brazilian National Research Agency estimated block models, the original values were reproduced with less than a $10 \%$ relative deviation.

in the estimates performed by KMAF with respect to the classical co-kriging approach.

Moreover, analyzed was the similarity between the estimates obtained through both approaches. The linear coefficient of correlation between the KMAF block model and the co-kriging block model for all three variables exceeds for all cases. There is a great similarity between the estimates obtained through both methods. The dispersion cloud is symmetric around the perfect correlation $(\mathrm{x}=\mathrm{y})$. the method does not expect the same spatial behavior amongst variables. The cross validation shows that the KMAF method is applicable to a multivariate data set, and in this case study led to results as satisfactory as those obtained by co-kriging. However, the gain of using the KMAF method is that, different from co-kriging, it does not have to attend to the LMC positive condition, which can be a troublesome task in cases that involve more than three variables.

The original data correlation is reproduced by the proposed method; moreover, the swath plots showed consistency between the results obtained by $\mathrm{KMAF}$ and co-kriging and the original data. This suggests the variable decorrelation prior to the estimation process is valid, since the results do not show significant loss of accuracy, thus avoiding the use of LMC.
(CNPq) and Vale S.A. for supporting the Mineral Exploration and Mining Plan- ning Research Unit (LPM) at the Universidade Federal do Rio Grande do Sul.

\section{References}

BANDARIAN E. M.; BLOOM, L. M.; MULLER, U. A. Direct minimum/maximum autocorrelation factors within the framework of two structure model of coregionalization, Computers and Geoscience, v. 34, n. 3, p.190-200, 2008.

DESBARATS, A. J.; DIMITRAKOPOULOS, R. Geostatistical simulation of regionalized pore-size distributions using min/max autocorrelation factors, Mathematical Geology, v. 32, n. 8, p.919-942, 2000.

DIRICHLET, G. L. Über die Reduktion der positive quadratiskenformem mi dreiunbestimmtenganzen Zahlen, Journal für die reineundange wand te Mathematik, v. 40, p. 209-227, 1850.

GOOVAERTS, P. Geostatistics for natural resource evaluation. Oxford University Press, 1997. 483p.

MARECHAL, A. Cokrigeage et régression en correlation intrisèque. Ecoledes Mines de Paris, 1970. 40p. (Technical Report 205).

MATHERON, G. Principles of geostatistics, Economic Geology, v. 58, n.8, p. $1246-$ 1266, 1963.

PEARSON, K. On lines and planes of closest fit to systems of points in space, Philosofical Magazine, v. 2, n. 6, p. 559-572, 1901.

SWITZER, P., GREEN, A. A. Min/max autocorrelation factors for multivariate spatial imagery. Stanford University, 1984. 14 p. (Technical Report 6). 